\title{
Penjelasan Materi Mengenai Proses Sistem Operasi
}

\author{
Muhammad Rizq Daffa Jodi \\ 195120026 \\ Fakultas Komputer \\ daffajody.students@umitra.ac.id
}

Sistem operasi modern merupakan suatu sistem yang beesar dan kompleks sehingga strukturnya harus dirancang dengan hati hati dan saksama supaya dapat berfungsi seeperti yang di inginkan serta dapat dimodifikasi dengan mudah

Kemudian struktur monolithic

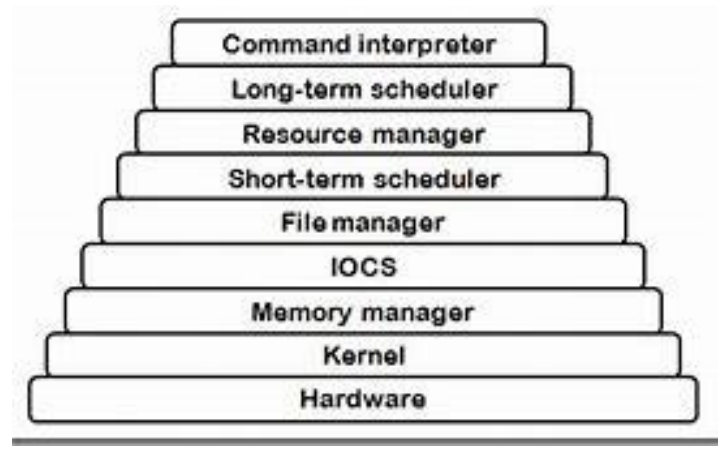

Struktur sistem operasi di sistem ini tidak terstruktur. Sistem operasi sebagai kumpulan prosedur yang masing-masing dapat saling dipanggil jika dibutuhkan. Setiap prosedur yang ada di dalam sistem ini mempunyai interface yang sudah didefinisikan dengan baik. 


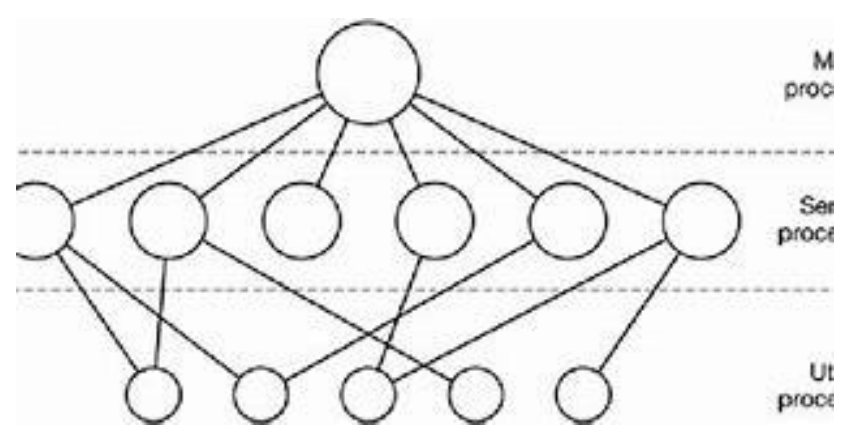

Sistem pertama yang dibangun dengan sistem lapisan adalah THE yang dibuat di Technische Hogeschool Eindhoven, Belanda pada tahun 1968 oleh E.W. Dijkstra dan para mahasiswanya.Sistem ini mempunyai enam lapis.

Lapisan 5 : user program

Lapisan 4 : buffering untuk I/O device

Lapisan 3 : operator-console device driver

Lapisan 2 : manajemen memori

Lapisan 1 : penjadwalan CPU

LApisan 0 : Hardware

Struktur Lapisan ( VENUS)

sistem Venus yang mempunyai tujuh lapisan. Lapisan bawah (0 sampai 4) digunakan oleh penjadwalan CPU dan manajemen memori yang kemudian diletakkan dalam suatu microcode.

\section{Mesin Virtual}

Secara konsep, sistem computer dibuat berdasarkan lapisan. Hardware atau perangkat lunak merupakan tingkatan terbawah dari keseluruhan sistem. Kernel yang berjalan ditingkatan berikutnya menggunakan instruksi-intruksi perangkat keras untuk membuat kumpulan sistem call yang digunakan oleh lapisan luarnya.

Dalam beberapa hal, program sistem tidak membedakan kedua lapisan tersebut. 
Model client server

Dalam model ini, semua kernel bekerja menangani komunikasi antara server dan client. Dengan membagi sistemoperasi

menjadi banyak bagian yang masing-masing hanya menangani bagian tertentu dari sistem. Seperti layanan file, layanan proses, layanan terminal memori maka setiap bagian menjadi kecil dan lebih mudah diatur.

\section{Materi Proses}

Proses adalah sebuah konsep utama pada sistem operasi, sehingga masalah manajemen proses adalah masalah utama pada perancangan sistem operasi. Proses sistem operasi Untuk kegiatan proses, sistem operasi berperan untuk mengelola segala proses pada sistem dan mengalokasikan sumber daya ke proses tersebut.

Status sistem operasi

Meskipun pada setiap proses terdiri dari suatu kesatuan yang terpisah, tetapi adakalanya proses-proses tersebut butuh saling berinteraksi. Satu proses dapat dibangkitkan dari output proses lainnya sebagai input.

\section{PCB}

Setiap proses direpresentasikan / digambarkan oleh sistem operasi dengan menggunakan Process Control Block (PCB). 


\section{A. ID SECURITY}

QWTD44112377-ASP-524414475

\section{B. REFERENCE}

[1] O. M. Febriani and A. S. Putra, "Sistem Informasi Monitoring Inventori Barang Pada Balai Riset Standardisasi Industri Bandar Lampung," J. Inform., vol. 13, no. 1, pp. 90-98, 2014.

[2] A. S. Putra, "Paperplain: Execution Fundamental Create Application With Borland Delphi 7.0 University Of Mitra Indonesia,” 2018.

[3] A. S. Putra, "2018 Artikel Struktur Data, Audit Dan Jaringan Komputer," 2018.

[4] A. S. Putra, "ALIAS MANAGER USED IN DATABASE DESKTOP STUDI CASE DB DEMOS."

[5] A. S. Putra, "COMPREHENSIVE SET OF PROFESSIONAL FOR DISTRIBUTE COMPUTING."

[6] A. S. Putra, "DATA ORIENTED RECOGNITION IN BORLAND DELPHI 7.0."

[7] A. S. Putra, "EMBARCADERO DELPHI XE 2 IN GPU-POWERED FIREMONKEY APPLICATION."

[8] A. S. Putra, "HAK ATAS KEKAYAAN INTELEKTUAL DALAM DUNIA TEKNOLOGY BERBASIS REVOLUSI INDUSTRI 4.0.” 
[9] A. S. Putra, "IMPLEMENTASI PERATURAN PERUNDANGAN UU. NO 31 TAHUN 2000 TENTANG DESAIN INDUSTRI BERBASIS INFORMATION TECHNOLOGY."

[10] A. S. Putra, "IMPLEMENTATION OF PARADOX DBASE."

[11] A. S. Putra, "IMPLEMENTATION OF TRADE SECRET CASE STUDY SAMSUNG MOBILE PHONE."

[12] A. S. Putra, "IMPLEMENTATION PATENT FOR APPLICATION WEB BASED CASE STUDI WWW. PUBLIKLAMPUNG. COM.”

[13] A. S. Putra, "IMPLEMENTATION SYSTEM FIRST TO INVENT IN DIGITALLY INDUSTRY."

[14] A. S. Putra, "MANUAL REPORT \& INTEGRATED DEVELOPMENT ENVIRONMENT BORLAND DELPHI 7.0.”

[15] A. S. Putra, "PATENT AS RELEVAN SUPPORT RESEARCH.”

[16] A. S. Putra, "PATENT FOR RESEARCH STUDY CASE OF APPLE. Inc."

[17] A. S. Putra, "PATENT PROTECTION FOR APPLICATION INVENT."

[18] A. S. Putra, "QUICK REPORT IN PROPERTY PROGRAMMING."

[19] A. S. Putra, "REVIEW CIRCUIT LAYOUT COMPONENT REQUIREMENT ON ASUS NOTEBOOK."

[20] A. S. Putra, "REVIEW TRADEMARK PATENT FOR INDUSTRIAL TECHNOLOGY BASED 4.0.”

[21] A. S. Putra, "TOOLBAR COMPONENT PALLETTE IN OBJECT ORIENTED PROGRAMMING."

[22] A. S. Putra, "WORKING DIRECTORY SET FOR PARADOX 7."

[23] A. S. Putra, "ZQUERY CONNECTION IMPLEMENTED PROGRAMMING STUDI CASE PT. BANK BCA Tbk."

[24] A. S. Putra, D. R. Aryanti, and I. Hartati, "Metode SAW (Simple Additive Weighting) sebagai Sistem Pendukung Keputusan Guru Berprestasi (Studi Kasus: SMK Global Surya)," in Prosiding Seminar Nasional Darmajaya, 2018, vol. 1, no. 1, pp. 85-97.

[25] A. S. Putra and O. M. Febriani, "Knowledge Management Online Application 
in PDAM Lampung Province," in Prosiding International conference on Information Technology and Business (ICITB), 2018, pp. 181-187.

A. S. Putra, O. M. Febriani, and B. Bachry, "Implementasi Genetic Fuzzy System Untuk Mengidentifikasi Hasil Curian Kendaraan Bermotor Di Polda Lampung," SIMADA (Jurnal Sist. Inf. dan Manaj. Basis Data), vol. 1, no. 1, pp. 21-30, 2018.

[27] A. S. Putra, H. Sukri, and K. Zuhri, "Sistem Monitoring Realtime Jaringan Irigasi Desa (JIDES) Dengan Konsep Jaringan Sensor Nirkabel," IJEIS (Indonesian J. Electron. Instrum. Syst., vol. 8, no. 2, pp. 221-232.

[28] D. P. Sari, O. M. Febriani, and A. S. Putra, "Perancangan Sistem Informasi SDM Berprestasi pada SD Global Surya," in Prosiding Seminar Nasional Darmajaya, 2018, vol. 1, no. 1, pp. 289-294. 